\title{
Assessment of behavior of two-shelled domes in Iranian traditional architecture: the Charbaq School, Isfahan, Iran
}

\author{
M. Ghasempourabadi ${ }^{1}$, V. R. Mahmoudabadi Arani ${ }^{2}$, \\ O. Bahar ${ }^{2} \&$ M. Mahdavinejad ${ }^{3}$ \\ ${ }^{1}$ Faculty of Architecture, Art University, Tehran, Iran \\ ${ }^{2}$ Structural Dynamics Dept., International Institute of Earthquake \\ Engineering and Seismology (IIEES), Tehran, Iran \\ ${ }^{3}$ Faculty of Art and Architecture, Tarbiat Modares University, \\ Tehran, Iran
}

\begin{abstract}
The eye-catching structure of domes is one of the most significant archetypes of the traditional architecture of Iran. Review of the merits of the architecture of Iranian monuments show that domes, which are the masterwork of traditional builders, are constructed in various shapes by various techniques in different periods over centuries. Two-shelled domes are the result of the technical evolution of traditional technology of historic architecture in the construction of regular domes. In an earlier historical age, many of the mosques of Iran, schools and building complexes were covered by single- or two-shelled domes. But, these domes are in urgent need of technical assessment: modeling, load transfer mechanisms, element characteristics, evaluation criteria, and shape effects. The aim of this paper is to explain how two-shelled domes behave in the structural systems of traditional architecture of Iran, how they bear and transfer various types of loadings and why the two-shelled dome is used instead of the oneshelled dome.

In this paper as a case study, the two-shelled dome of the Charbaq School of Isfahan constructed in the Safavid era has been selected. The dome is modeled in simulation software and then its behavior under vertical loadings, dead and live loads, horizontal loadings, and wind and earthquake loads are examined in detail. In this way, performance of the two-shelled dome during a variety of loading
\end{abstract}


conditions is assessed. Extensive analysis shows that assessment of behavior of the mentioned two-shelled dome is essentially based on many different items such as modeling, parameter values, connection details, and general failure criteria and its behavior is far superior to the similar one-shelled dome with similar parameters.

Keywords: two-shelled dome, single shelled domes, traditional architecture of Iran, structural systems, Isfahan, Charbaq School, membrane behavior.

\section{Introduction}

Iran is an ancient country, which consists of a great culture and history. Over centuries, Iranian architecture has developed gradually. During this historical era, construction phenomena have changed little by little until an optimized form has been achieved, namely domes. Domes have an old background as ceilings of large places in Iranian architecture. In the Iranian plateau, which is hot and dry, Iranians rarely use flat ceilings because of the insufficiency of appropriate long and strong timbers. On the other hand, this plateau is abundant with rich soil that allows the use of domes for covering wide spans. Another reason for using domes is the climatic situation, in which the curve vault and domes play an important role in a hot and dry area such as Iran. The dome as a ceiling has changed over history and finally a complete shape has been achieved. Singleshelled domes (which are the earliest types of domes) and two-shelled domes (a discontinuous type) are completely different from the continuous type of twoshelled dome in a load bearing situation, because in the continuous type of dome there are many different members that are treated as structural members. Charbaq School's dome which was completed in the Safavid era is special and very important among the continuous two-shelled domes, because it benefits from two completely separate shells where, between them, many structural members help to bear loads.

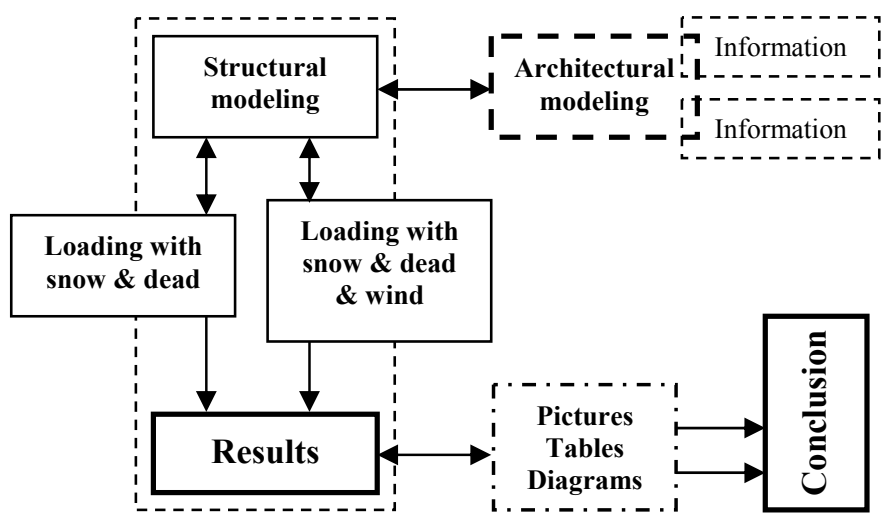

Figure 1: Research method and deduction mechanism.

In trying to discover the reason why instead of the traditional single type of dome, they have used continuous two-shelled domes, and also how does each 
structural member of the dome behave, requires an exact assessment and analysis which fortunately can be made by structural software.

Discovering the construction of the load bearing method and the structural manner of this type of dome is the key to solving several structural problems which emerge when covering wide spans.

\section{Domes in general view}

In the geometrical definition, the dome is a geometrical place of points that result from spinning an arch around a vertical axis. But in architectural language, the dome is a covering established over a circular context. It is usually established on a circular context and is based on three parts: 1_Gonbad-khane: the context of the dome and the place which the dome covers, $\overline{2}$ _Bashn: a cubic form of the place on to which the dome establishes itself directly and this is on the roof, 3 Chapire: in Iranian architecture rarely is the cubic context used for domes, but with Chapire they convert the cubic plan into a circular type and after that establish a dome on it (Pirnia [1]).

Stability is very important for building domes; builders have solved this problem in various ways. In domes, as in arches, the method of load transferring has to result in a situation where the forces pass through one-third of every section of the shell's thickness. If one were to draw a sliced section of the shell, it is clear that there are diagonal forces in addition to sideway forces, so this causes the domes to behave as a double-directional arch (Guerra [2]).

\subsection{Typology of domes in Iranian traditional architecture}

Construction of domes has been different at various periods in time. Iranian domes are divided into six variant types: 1 - single shell dome, 2 - continuous two-shelled dome, 3 - discontinuous two-shelled dome, 4 - single shelled and two-shelled domes with a narrow vault, $5-$ Rok domes (the shape of this dome is similar to a cone or pyramid), 6 - triple shelled dome (Pirnia [1]).

\subsection{Construction methods}

Domes have been built by three methods where each is different in load bearing capacities. In the first method (corbelled), bricks are placed with horizontal courses and the upper row of bricks protrudes over the lower row at the center. In the second method, the direction of bricks is always normal to the generation curve of the dome surface. In the third method, a few ribs are first erected, after which bricks are put between them to complete the dome (Hejazi [3]).
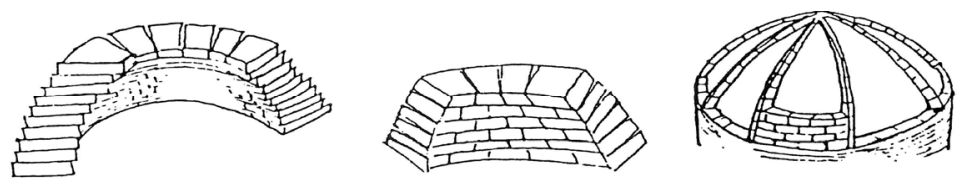

Figure 2: Three methods of dome construction. 


\subsection{Isfahan Charbaq School dome}

There are many aspects for making two-shelled domes, establishing that the second dome enhances the building's greatness and affects its aesthetics. The curve lines which appear with the upper shell raise the view up to the crown and cause to pacify the viewers.

This dome is a two-shelled continuous type and is constructed within 8 narrow ribs and 8 physical membranes between them. The upper shell is based on 8 brick structural members with a $38 \mathrm{~cm}$ width and $40 \mathrm{~cm}$ height on the lower shell which are called Khashkhashi. These members are $40 \mathrm{~cm}$ in width and about $2 \mathrm{~m}$ in height finishing under the upper shell, improving the load bearing capacity. Also the dimension of the square plan that is under the dome is $13 \times 13 \mathrm{~m}^{2}$ and the span of the inner dome is about $13 \mathrm{~m}$ (Memarian [4]).
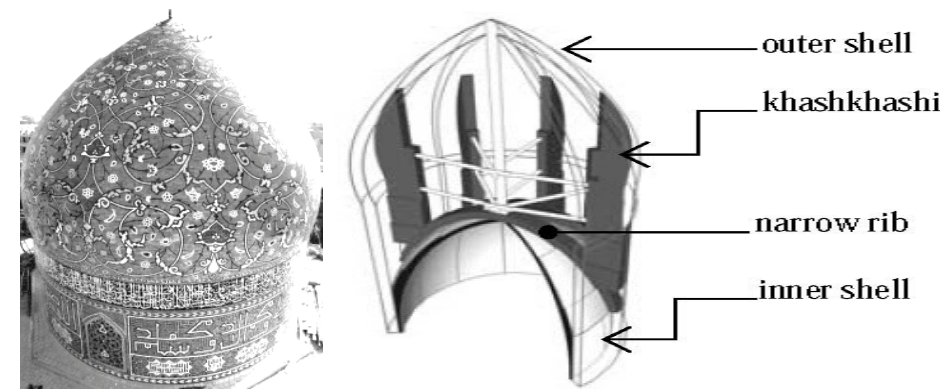

Figure 3: Image and structure of the Charbaq two-shelled continuous dome.

\section{Structural assessment and analysis}

Since such old structures have been constructed with massive brittle materials to a great extent, preliminary linear elastic finite element analysis is considered the most realistic analysis for them. In this regard, we use the finite element Auto desk Robot Structural Analysis Professional 2011 program, which is a program in widespread use, to reasonably assess real behaviors of complex structures during different load combinations. In order to model the above mentioned dome a few assumptions are made: (1) All the materials used in the two- or one-shelled domes are only masonry. (2) The masonry behaves as a linear elastic material, where its properties are defined in [3], and tabulated in Table 1. Note that the allowable stresses are larger than values usually accepted in areas with high seismic activities. Since Isfahan is located in a low seismic zone, these parameters are almost acceptable. (3) Materials are assumed to be isotropic. So, compression, tension, and shear force in any direction (principal directions) may compare with the allowable values. (4) In this paper it is assumed that the whole constructed dome is placed on a firm place and its supports are totally fixed.

Three types of common structural loads, i.e. dead load, snow load, and wind load, are determined based on the structure and area specifications. Different combinations of these loadings defined by "Loading Codes" are applied to the 
dome structures. In order to compare the behavior of both one- and two-shelled domes, results of the maximum values of deformations and principal stresses are detected, considered, and discussed, in detail.

Table 1: $\quad$ Material properties for masonry brick domes [3].

\begin{tabular}{ccccccc}
\hline $\begin{array}{c}\text { Modulus of } \\
\text { elasticity }\end{array}$ & $\begin{array}{c}\text { Poisson } \\
\text { ratio }\end{array}$ & $\begin{array}{c}\text { Weight } \\
\text { density }\end{array}$ & $\begin{array}{c}\text { Allowable } \\
\text { compressive } \\
\text { stress }\end{array}$ & $\begin{array}{c}\text { Allowable } \\
\text { tensile } \\
\text { stress }\end{array}$ & $\begin{array}{c}\text { Allowable } \\
\text { shear } \\
\text { stress }\end{array}$ & $\begin{array}{c}\text { Allowable } \\
\text { bearing } \\
\text { stress }\end{array}$ \\
$E$ & $v$ & $\begin{array}{c}\gamma \\
f_{c}\end{array}$ & $\begin{array}{c}f_{c} \\
\mathrm{~N} / \mathrm{mm}^{2}\end{array}$ & $\begin{array}{c}f_{t} \\
\mathrm{~N} / \mathrm{mm}^{2}\end{array}$ & $\begin{array}{c}f_{v} \\
\mathrm{~N} / \mathrm{mm}^{2}\end{array}$ & $\begin{array}{c}f_{b} \\
\mathrm{~N} / \mathrm{mm}^{2}\end{array}$ \\
\hline $7.358 \times 10^{3}$ & 0.1 & $18.541 \dagger$ & 0.7 & 0.2 & 0.1 & 0.7 \\
\hline
\end{tabular}

\subsection{Loading}

In this paper, only two different combinations of the defined loads according to the common building codes are considered, which are defined as follows:

Combo1: $\mathrm{D}+\mathrm{S}$

Combo2: $0.75(\mathrm{D}+\mathrm{S}+\mathrm{W})$

where:

$\mathrm{D}=$ dead load; total weight of the whole parts of the structure

$\mathrm{S}=$ unsymmetrical snow load

$\mathrm{W}=$ wind load.

These are commonly defined load conditions on the structure at normal and special conditions. Considering a symmetrical vertical dead load besides an unsymmetrical snow load produces more critical conditions for the building. When environmental lateral loading besides vertical loadings affect the building, additional allowable stresses are permitted. For this purpose, the additional coefficient of 0.75 appears in Combo2. Other conditions may be considered as combining lateral loads with decreased vertical loadings.

\subsection{Analysis under combination of dead and unsymmetrical snow loads}

In the past, safe construction was guaranteed by constructing massive and overdesigned structures. Hence, it seems that using these combinations of loads may not cause any difficulty for such a strong building. Combol only shows how the vertical loads produce the worst conditions throughout the structure. Results of the deformation and principal stress development through the one- and two-shelled domes under a linear static analysis are summarized in Table 2, and are presented in Figures 4, 5 and 6. Referring to Table 2, one may be surprised because it is clear that omitting the inner dome causes a decrease in all stress and deformation values of the structure. The stresses are much smaller than the allowable values presented in Table 1 . Hence, we can conclude that the structure is very strong against vertical environmental loads even when the inner dome fails. It should be mentioned that the stability and large deformation of the base 
Table 2: Comparing deformations and maximum stresses in the one- and two-shelled domes under a combination of dead and unsymmetrical snow loads.

\begin{tabular}{|c|c|c|c|c|c|c|}
\hline \multirow{2}{*}{$\left(\begin{array}{c}|c| \\
(\text { dead+snow })\end{array}\right.$} & \multicolumn{3}{|c|}{$\begin{array}{c}\text { Max. Principal Stresses } \\
(\mathrm{kPa})\end{array}$} & \multicolumn{3}{c|}{ Max. Deformations } \\
& \multicolumn{3}{|c|}{$(\mathrm{mm})$} \\
\cline { 2 - 7 } & comp. & tension & shear & horiz. & vert. & total \\
\hline Two-Shelled & 16.30 & 11.05 & 10.63 & 1.41 & 1.73 & 1.90 \\
\hline One-Shelled & 15.31 & 8.62 & 11.93 & 1.26 & 1.62 & 1.84 \\
& & & & & & \\
\hline
\end{tabular}
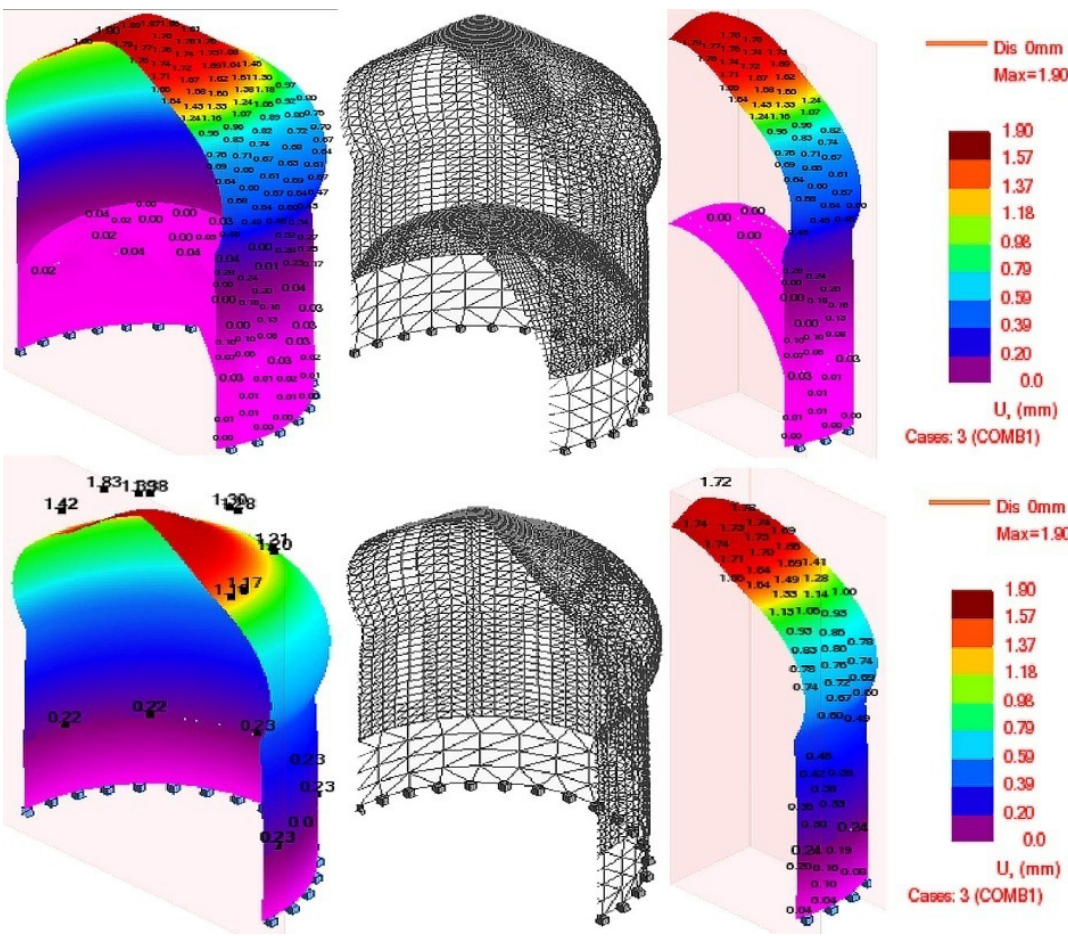

Cases: 3 (COMB1)

Figure 4: Comparing total deformations in the one- and two-shelled domes under combination of dead and unsymmetrical snow loads. 
cylinders are not considered in the linear static analysis. The inner dome has a major role to in safeguarding the whole structure and guaranteeing its stability during vertical or horizontal loadings.

Comparing colors as a criterion of the total deformation of different parts of the structure in Figure 4 shows, although the deformation is so small (below $2 \mathrm{~mm}$ ), their developments from the apex to the base; everywhere through the main shell, middle cylinder, or base cylinder are extended from a one- to twoshelled dome. Hence, the existence of the inner dome may decrease the surface deformations especially at the base of the building.

In Figures 5 and 6 the principal stress distributions due to vertical loads are shown. While the values tabulated in Table 2 emphasize that stresses transmitting through the two-shelled structure are larger, Figure 5 shows that the distribution of principal shear stresses in the one-shelled dome are more critical. However, there is no sensible difference between distributions of the other principal stresses, like s1 in Figure 6.

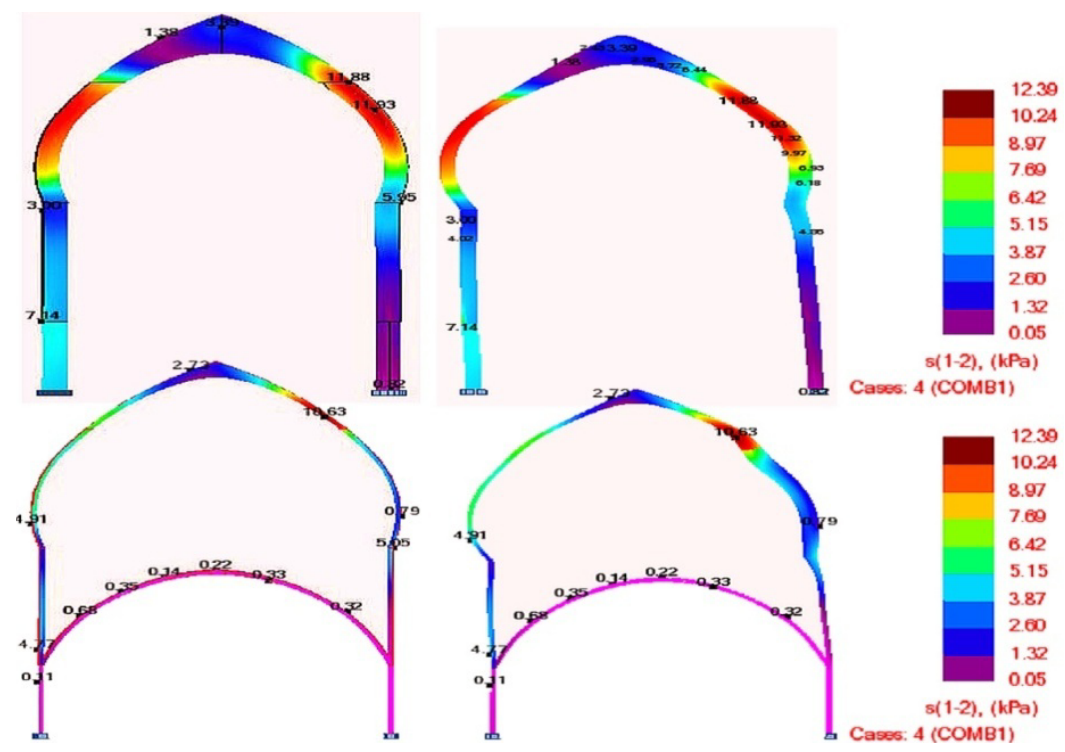

Figure 5: Comparing principal shear stresses in the one- and two-shelled domes under combination of dead and unsymmetrical snow loads.

\subsection{Analysis under combination of dead, unsymmetrical snow, and wind loads}

Combo2 notices the effect of a lateral load when vertical loads exist. Using an unsymmetrical snow load may alter the distribution of the stresses along the structure. Adding a lateral load on the previous vertical loads may increase the unsymmetrical deformations or stresses so that the worst condition appears. 
Results of deformations and the principal stress distribution throughout the oneand two-shelled domes under a linear static analysis are summarized in Table 3, and are presented in Figures 7 and 8.

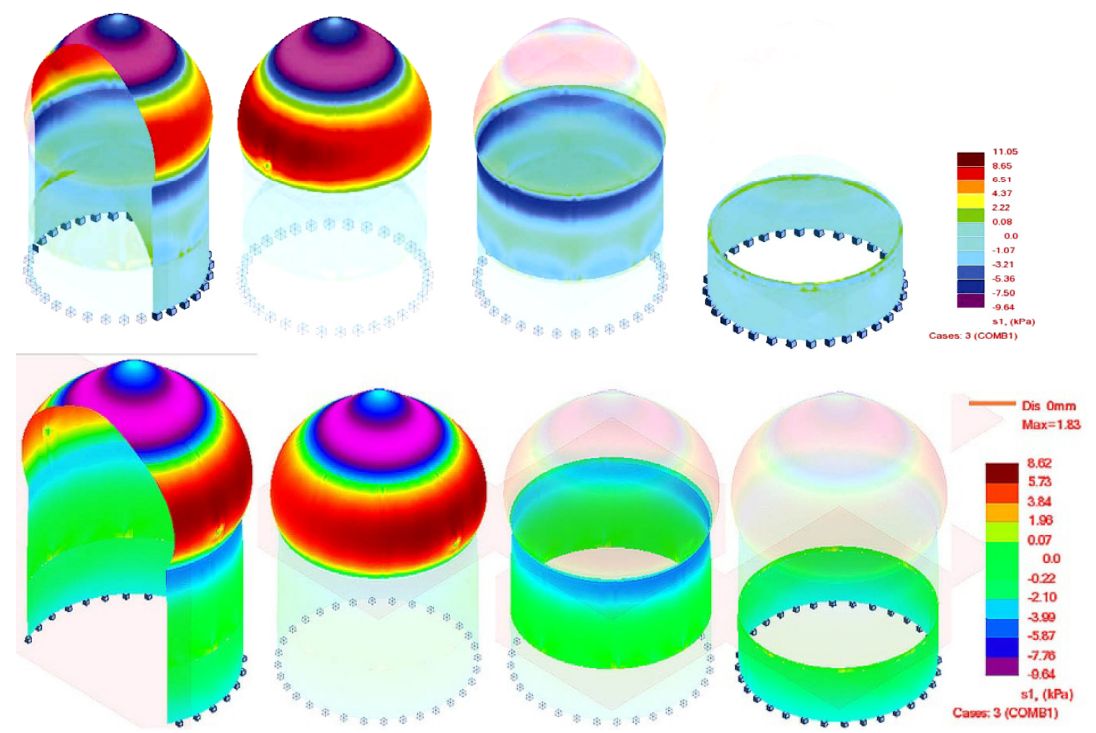

Figure 6: Comparing principal stresses in the one- and two-shelled domes under combination of dead and unsymmetrical snow loads.

Referring to Table 3 , it is clear that omitting the inner dome results in increasing all the deformations and stresses, especially the compression principal stress and total deformation. By noting Figure 7, in the one-shelled dome it can be seen that a much larger deformation is spread around the whole surface of the dome and transmitted to the base of the building.

The principal shear stresses drawn in Figure 8 confirm the previous results. This means that the inner dome definitely increases the lateral stiffness of the building. Therefore, it is a vital part of such a tall base dome.

Table 3: Comparing deformations and maximum stresses in the one- and two-shelled domes under combination of dead, unsymmetrical snow, and wind loads.

\begin{tabular}{|c|c|c|c|c|c|c|}
\hline \multirow{2}{*}{$0.75($ dead+snow+wind) } & \multicolumn{3}{|c|}{$\begin{array}{c}\text { Max. Principal Stresses } \\
(\mathrm{kPa})\end{array}$} & \multicolumn{3}{c|}{$\begin{array}{c}\text { Max. Deformations } \\
(\mathrm{mm})\end{array}$} \\
\cline { 2 - 7 } & comp. & tension & shear & horiz. & vert. & total \\
\hline Two-Shelled & 13.11 & 7.43 & 8.17 & 1.03 & 1.38 & 1.40 \\
\hline One-Shelled & 21.10 & 9.00 & 9.29 & 1.72 & 2.08 & 2.40 \\
\hline
\end{tabular}




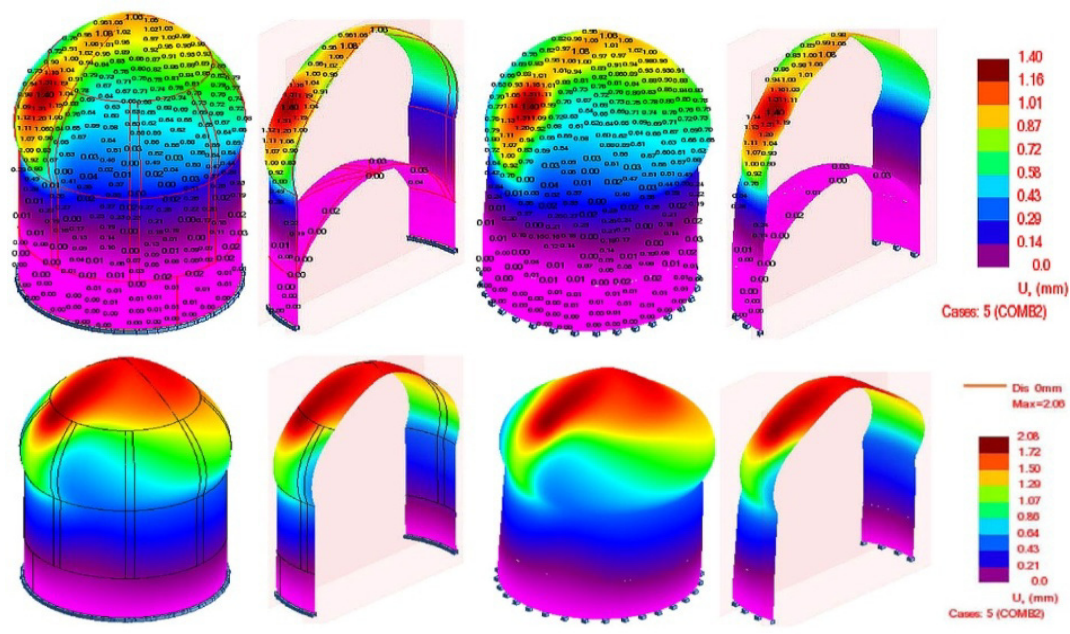

Figure 7: Comparing total deformations in the one- and two-shelled domes under combination of dead, unsymmetrical snow, and wind loads.

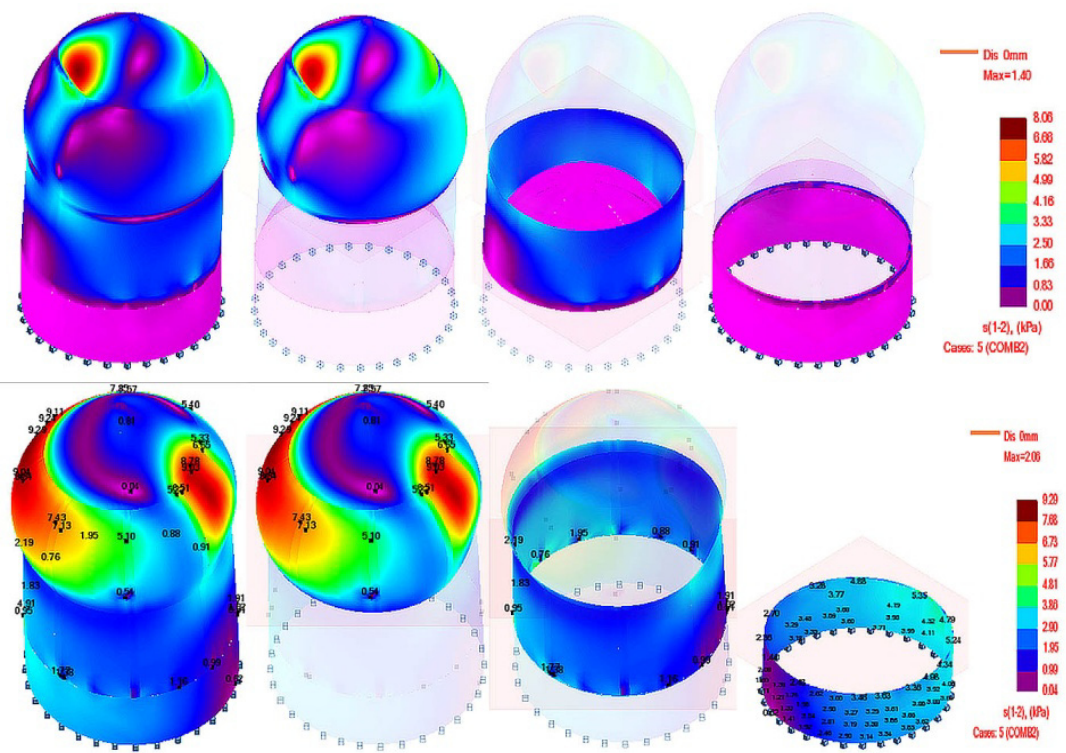

Figure 8: Comparing principal stresses in the one- and two-shelled domes under combination of dead, unsymmetrical snow, and wind loads. 


\subsection{Stability and long height support}

Since, the mentioned building is spread over a large area in the plan, it seems that the main factor causing the height of the considered dome to be very tall was its visibility from the viewpoint of the beholders standing or passing the street. But, it has a negative effect on the stability of the dome. Under such conditions, the cylindrical wall supporting the dome needs some stiffeners to act well in transmitting loads without sustaining crack growth, occasioning local instability or total failure under different conditions. Hence, inserting an inner dome was inevitable to ensure that the main dome would perform well. In other words, the inner dome was constructed to restrain the tall cylindrical wall supplying the main support of the outer dome.

\section{Conclusions}

In this paper, the linear elastic behavior of a traditional construction of a twoshelled dome belonging to the Safavid era, Charbaq School's dome, is investigated. Behavior of this dome under different loading conditions is compared to a similar dome without an inner dome. Two combinations are examined: dead and unsymmetrical snow loads, and the effect of lateral wind load on this combination. A two-shelled dome under unsymmetrical vertical loads suffers larger values of total deformations and principal stresses. However, distribution of large deformation and stresses through the structure of the oneshelled dome is much larger in comparison with the two-shelled dome.

On the other hand, various analyses show that inserting a lateral load completely changed the results. The two-shelled dome performs well against external loads such that distribution of large deformations and principal stresses are restricted to a limited surface area, while in the one-shelled dome (obtained by omitting an inner dome) the maximum values of deformations and stresses are larger and spread out near the whole of the surface. Anyway, since the stresses are much smaller than the allowable values, the building is too strong against common vertical and environmental lateral loadings.

Finally, it should be remembered that all analyses are linear elastic, therefore the inelastic behavior of materials, large deformation of the structure, crack growth and expansion, local failure of members, and total collapse of the structure, are not considered. Although all the principal stresses are limited within the allowable values, applying earthquake loads besides the vertical loads, and defining more critical allowable stresses for seismic-prone areas (which are much less than defined values) give a better estimation of performance of the two-shelled dome.

\section{References}

[1] Pirnia, M.K., "Dome in Iranian Architecture" (in Persian), Asar, 8, pp 54$121,1991$.

[2] Guerra, G., "Statica e tecnica costruttiva delle couple antiche e modern", Ed. universita di Napoli, p 22, 1958. 
[3] Hejazi, M., "Historical Buildings of Iran: Their Architecture \& Structure", WIT Press, Southampton, pp 53-74, 1997.

[4] Memarian, G.H, "Statics of vaulted structures in Islamic architecture of Iran" (in Persian), Elm-O-Sanaat University press, Tehran, pp 239-365, 1988.

[5] Pirnia, M.K. and Memarian, G.H. "Styles of Iranian Architecture" (in Persian). Iran, Bonyad Publications, 1991.

[6] Mehdizadeh Saradj, F., "Unreinforced masonry domed buildings in regions of high seismic risk of Iran: a procedure for selecting historic buildings for protection and repair". Unpublished $\mathrm{PhD}$ thesis. Sheffield, Sheffield University, 2004.

[7] Summary of "Building Codes for Earthen Buildings in Seismic Areas: The Peruvian Experience" by J. Vargas, M. Blondet and N. Tarque; Proceedings of the 8th U.S. National Conference on Earthquake Engineering, April 2006), San Francisco, California, USA, 2006. 